\title{
Pharmacognostic Specification and Mangiferin Content of Aquilaria crassna Leaves
}

\author{
Worathat Thitikornpong ${ }^{1}$, Boonsri Ongpipattanakul ${ }^{2}$, Chanida Palanuvej ${ }^{1}$, Nijsiri Ruangrungsi ${ }^{1,3^{*}}$
}

\section{Worathat Thitikornpong ${ }^{1}$, Boonsri Ongpipattanakul' Chanida Palanuvej', Nijsiri Ruangrungsi ${ }^{1,3 *}$}

${ }^{\prime}$ College of Public Health Sciences, Chulalongkorn University, Bangkok, THAILAND.

${ }^{2}$ CU Drug and Health Products Innovation Promotion Center, Faculty of Pharmaceutical Sciences, Chulalongkorn University, Bangkok, THAILAND.

${ }^{3}$ Faculty of Pharmacy, Rangsit University, Patumthani, THAILAND.

\section{Correspondence}

Nijsiri Ruangrungsi Ph.D

College of Public Health Sciences, Chulalongkorn University, Bangkok 10330, THAILAND.

Phone No: +662-218-8158

E-mail: Nijsiri.R@chula.ac.th

History

- Submission Date: 05-09-2017;

- Review completed: 20-11-2017;

- Accepted Date: 27-12-2017

DOI : 10.5530/pj.2018.2.51

Article Available online http://www.phcogj.com/v10/i2

\section{Copyright}

(C) 2018 Phcog.Net. This is an openaccess article distributed under the terms of the Creative Commons Attribution 4.0 International license.

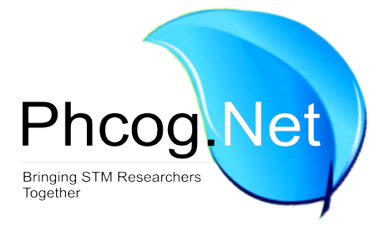

\begin{abstract}
Background: Aquilaria crassna Pierre ex Lecomte (Thymelaeaceae) has been used as a medicinal plant in many aspects. Previous research has revealed that $A$. crassna leaves contain mangiferin as an active compound. Although the active component has been investigated, the pharmacognostic specification and quantification of mangiferin from A. crassna leaves have never been established. Objective: The current study aimed to conduct and develop a pharmacognostic standard according to WHO guidance as well as the validated method for quantifying mangiferin content. Materials and Methods: Dried A. crassna leaves from 15 separated locations throughout Thailand were investigated for pharmacognostic specification. Their mangiferin contents were quantitatively analysed by TLC densitometry with winCATS software. Results: Macroscopic-, microscopic- characteristics and TLC fingerprinting combined with physicochemical parameters were reported in this study. The loss on drying, moisture content, and total ash content as well as acid-insoluble ash content were determined to be $8.62 \pm 0.13,8.16 \pm 0.14,6.82 \pm 0.09$ and $1.49 \pm 0.03 \%$, respectively. Ethanol- and waterextractive values were found to be $9.05 \pm 0.39$ and $16.94 \pm 0.22 \%$, respectively. In addition, the validation method for quantifying the mangiferin content was developed. The contents of mangiferin in A. crassna leaf extract determined by TLC-densitometry and TLC-image analysis were found to be $1.2992 \pm 0.5980$ and $1.3036 \pm 0.5874 \%$ by dried weight, respectively. The results between these two analytical methods were shown to have an insignificant difference. Conclusion: This study provides the necessary information for authentication and standardisation of $A$. crassna leaves.

Key words: Pharmacognostic specification, Aquilaria crassna leaves, Mangiferin, TLC-densitometry, TLC image analysis
\end{abstract}

\section{INTRODUCTION}

Aquilaria crassna Pierre ex Lecomte (Thymelaeaceae) is a medium-sized evergreen tree found throughout Southeast Asia and China. Agarwood has been a part of Ayurvedic, traditional Chinese medicine and traditional Thai medicine for centuries. This plant is not only wellknown in aromatherapy uses, but also recognised as herbal medicine for the treatment of various diseases as a sedative, analgesic, and digestive. ${ }^{1}$ Previous studies on the leaves of A. crassna revealed that it contained various potential activities as an anti-hyperglycemic, ${ }^{2}$ antipyretic, analgesic, ${ }^{3}$ antioxidant ${ }^{4}$ and laxative.,6 Recently, mangiferin was identified as an active component in A. crassna leaves. ${ }^{7}$ Mangiferin is a potent antioxidant from various natural sources $8,9,10,11$ and has been reported for the treatment of diabetes, ${ }^{12,13,14,15,16}$ cancer, ${ }^{17}$ rheumatid arthritis, ${ }^{18}$ hypolipidemic, ${ }^{13}$ oxidative stress, ${ }^{19,20,21}$ and inflammation. ${ }^{22}$

Nowadays, the standardisation of herbal raw materials is necessary for quality control and therapeutic efficacy. The method for authentication, quality control and the validation process is still preferred for standardisation of herbal materials. Macroscopic, microscopic, and chemical fingerprinting are the routine procedures for medicinal plant materials identification, while physicochemical parameters and the content of active substances have been used to ensure quality. However, the scientific pharmacognostic parameters and simultaneous quantification of mangiferin using TLC method for standardisation of A. crassna leaves have never been established. Thus, this study aimed to evaluate the pharmacognostic parameters for identification of A. crassna leaves. In addition, TLC-densitometry and TLC image analysis were developed and validated for quantitative analysis of mangiferin content from A. crassna leaves collected from various locations throughout Thailand.

\section{MATERIALS AND METHODS}

\section{Plant materials}

Fifteen different samples of $A$. crassna leaves were collected during July to October 2014 from 11 provinces in Thailand. The samples were authenticated by Associate Professor Nijsiri Ruangrungsi and the voucher specimens were deposited at the College of Public Health Sciences, Chulalongkorn University, 
Thailand. The remaining leaves were dried, ground and stored at room temperature to protect them from light until needed.

\section{Chemicals}

Analytical grade reagents and solvents were used in this experiment. Mangiferin (purity $98.0 \%$ ) was purchased from Mira Biotechnology Co., Ltd., China. TLC plate was carried out on pre-coated silica gel GF sheets (Merck, Germany).

\section{Macroscopic and microscopic evaluation}

Macroscopic characteristics such as size, colour and other visible properties were noted. Transverse sections and ground powders were observed under a microscope to determine the anatomical and histological characteristics.

\section{Chemical fingerprinting}

The chemical profile of $A$. crassna ethanolic extract was examined using thin layer chromatographic techniques. The ethanolic extracts were accurately weighted and adjusted for volume to obtain a concentration of $10 \mathrm{mg} / \mathrm{ml}$. Three microliters of test solution were spotted onto a silicatype-TLC plate. The TLC plate was then developed with ethyl acetate: water: formic acid, as 17:3:2 v/v/v, respectively. The developed TLC plate was air-dried and examined under visible light and UV light (254 and $366 \mathrm{~nm}$ ). In addition, the TLC plate was sprayed with an anisaldehydesulphuric acid reagent then heated on a plate heater for $10 \mathrm{~min}$ before investigating the spot under visible light.

\section{Physicochemical studies}

Determination of loss on drying, total ash, acid-insoluble ash, ethanol and water extractive values, and water content were evaluated to establish the pharmacognostic specification of $A$. crassna leaves. The details of the methodology followed WHO guidance. ${ }^{23}$ Briefly, the loss on drying test was performed by drying the sample at $105^{\circ} \mathrm{C}$ until achieving constant weight. The total and acid-insoluble ashes left after burning at $500-600^{\circ} \mathrm{C}$ were determined for inorganic components. In addition, the moisture content was quantitated using the azeotropic distillation method. Extractable matter in absolute ethanol as well as water was determined by maceration to represent the amount of active constituents. All sampling was carried out in triplicate.

\section{Preparation of standard and sample solutions}

Stock solutions of mangiferin were prepared by dissolving in $85 \%$ ethanol in a volumetric flask at a concentration of $1 \mathrm{mg} / \mathrm{ml}$. The six working standard solutions (concentrations of $0.15,0.25,0.35,0.45,0.55$ and $0.65 \mathrm{mg} / \mathrm{ml}$ ) were diluted from a standard stock solution using ethanol as diluent.

Each sample of A. crassna leaves was weighed accurately (3.00 g) and extracted by soxhlet extraction with $95 \%$ ethanol until exhaustion. The extracts were filtered, evaporated using a rotary evaporator equipped with a vacuum pump and dried using freeze-dryer techniques. The extract powders were weighed and calculated for percentage yield. The dried extract was prepared by dissolving in absolute ethanol at a concentration of $1 \mathrm{mg} / \mathrm{ml}$. Each sampling was carried out in triplicate.

\section{Chromatographic conditions}

The solutions of mangiferin standard and ethanolic A. crassna extract were spotted as $5-\mathrm{mm}$. bands width onto the TLC plate coated with silica gel $60 \mathrm{GF}_{254}$ using a Linomat-5 automatic sample spotter. Each sample solution was done in triplicate. The mobile phase was composed of ethyl acetate: water: formic acid at 34:6:4 v/v/v, respectively. The TLC plate was developed in a developing chamber, which was pre-saturated with the mobile phase for $1 \mathrm{~h}$ at room temperature. The mobile phase was run to $80 \mathrm{~mm}$.

\section{TLC-densitometry and TLC image analysis}

The developed TLC plates were scanned densitometrically using a CAMAG TLC 3 Scanner in the absorbance mode at $254 \mathrm{~nm}$, which was operated by WinCATs software. While TLC image analysis was done using Image analysis software, the developed TLC plates were photographed under short wave $(254 \mathrm{~nm})$ ultraviolet light. The photo was taken using a TLC visualiser and saved as a TIFF file. The colour intensity of the mangiferin band was transformed into a chromatographic peak by ImageJ software. Six-point calibration of the two methods was done and each sample was quantified for the amount of mangiferin by peak area. Each sampling was carried out in triplicate.

\section{Validation method}

According to ICH guideline (Q2R1), the analytical method was validated for linearity, precision, accuracy, LOD, LOQ and robustness. ${ }^{24}$

\section{Statistical analysis}

The content of physicochemical parameters was calculated using grand mean and pooled standard deviation. Mangiferin content in each sample was calculated based on each extract yield. The contents between two analytical methods were compared statistically using a paired student t-test.

\section{RESULTS}

\section{Macroscopic and microscopic evaluation}

The morphological evaluation for identification of $A$. crassna was reported. A. crassna tree can grow to be up to $25-30 \mathrm{~m}$ tall. Its bark is brownish grey with leaves that are approximately $7.0-12.0 \mathrm{~cm}$ long and $2.5-5.0 \mathrm{~cm}$ wide with narrow elliptical or lanceolate shapes Figure 1A. The colour of the dried leaves for crude drug was green to brownish green. The sizes ranged from $5.0-10.0 \mathrm{~cm}$ long and $1.5-3.5 \mathrm{~cm}$ wide Figure $1 \mathrm{~B}$. The odour was pleasing with a slightly sweet taste.

Microscopic characteristics were investigated for both transverse section and powdered drug. Parenchyma and vascular bundle were found in the transverse section of the midrib. Furthermore, the $\mathrm{x}$-section of the midrib revealed that the epidermis was rectangular to round in shape Figure 2. In addition, the cells of the upper epidermis were larger than the lower epidermis. The lamina in the sectional view of the A. crassna leaves showed an upper epidermis, palisade and spongy parenchyma,
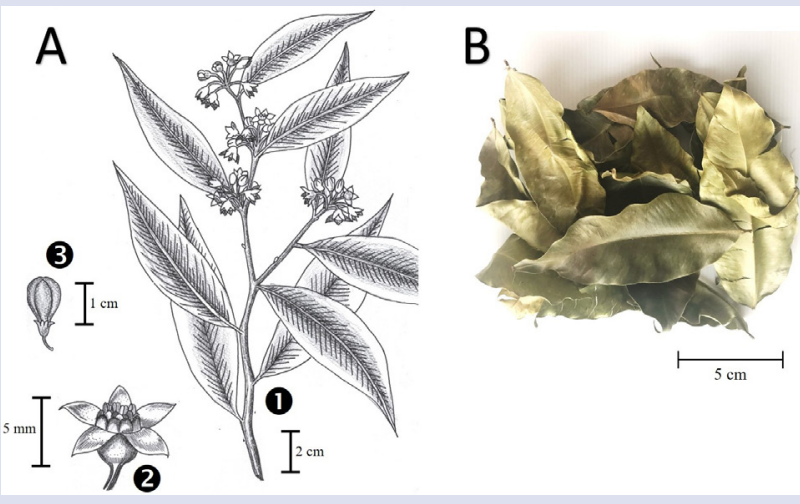

Figure 1: Macroscopic character of Aquilaria crassna A) drawing of plant; 1 - a part of branch, 2 - flower, 3-fruit and B) crude drug (leaves). 


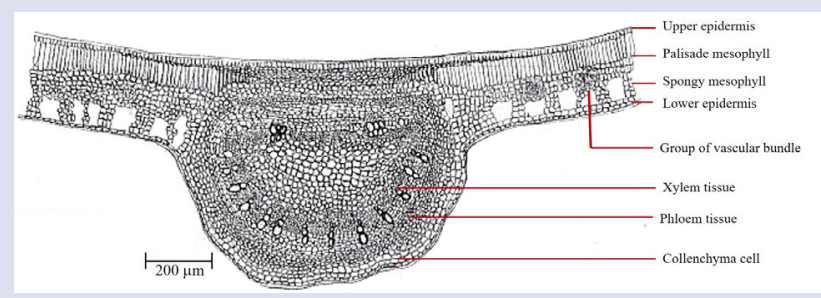

Figure 2: Microscopic characteristics of the transverse section of $A$. crassna midrib.

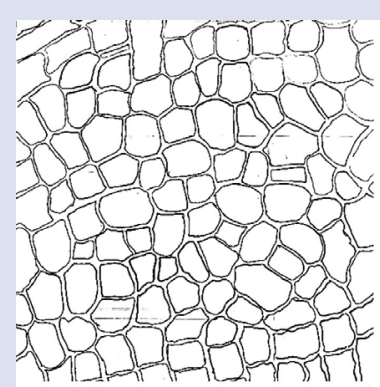

(A)

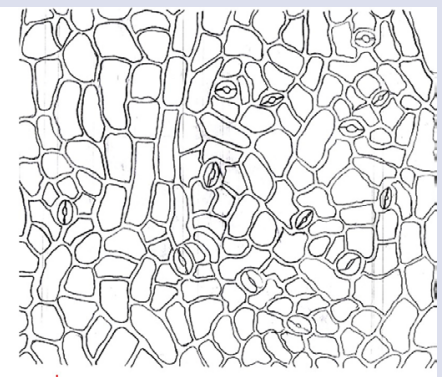

(B)
Figure 3: Microscopic characteristics of the surface views of A. crassna lamina. A) upper epidermis, and B) lower epidermis with anomocytic stomata.

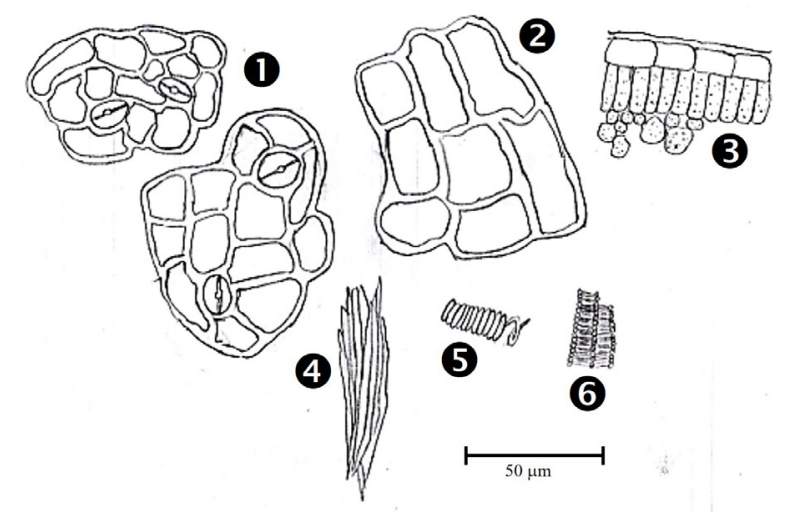

Figure 4: Microscopic characteristics of powdered A. crassna. 1) lower epidermis in surface view showing anomocytic stomata; 2 ) upper epidermis in surface view; 3 ) part of the lamina in sectional view, showing the upper epidermis, palisade mesophyll and part of spongy mesophyll; 4) group of lignified fibres; 5) part of spiral vessel; 6) part of reticulate vessel.

and lower epidermis. The upper epidermis comprised polygonal cells Figure 3A, while the lower epidermis had irregular shapes and the walls were slightly sinuous. Anomocytic stomata were only found in the lower epidermis Figure 3B. However, the powdered drug investigation showed some of the same microscopic characteristics such as anomocytic stomata with epidermal cell, part of the upper epidermis with part of palisade mesophyll, some fibres and vessels Figure 4.
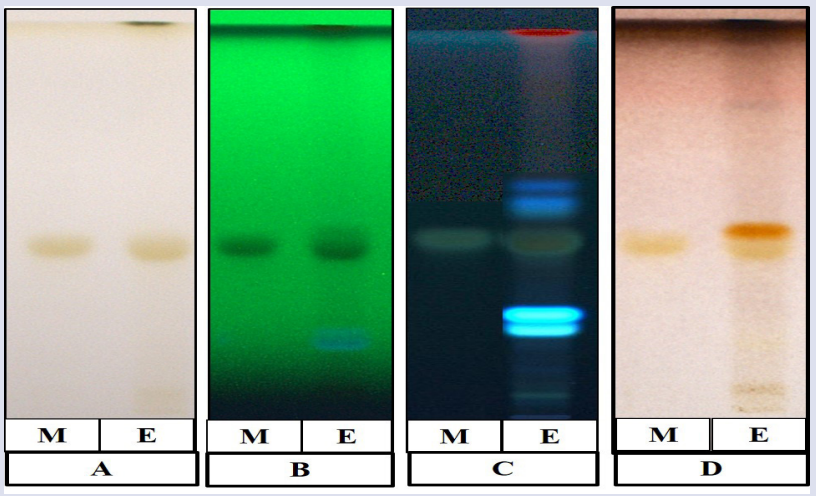

Figure 5: Thin layer chromatography fingerprinting of an ethanolic extract of dried A. crassna leaves (E) and mangiferin at concentration $0.4 \mathrm{mg} / \mathrm{ml}$ (M). A) appearance under visible light; B) under 254-nm UV light; C) under 365-nm UV light, and D) detection with anisaldehydesulphuric acid and heat.

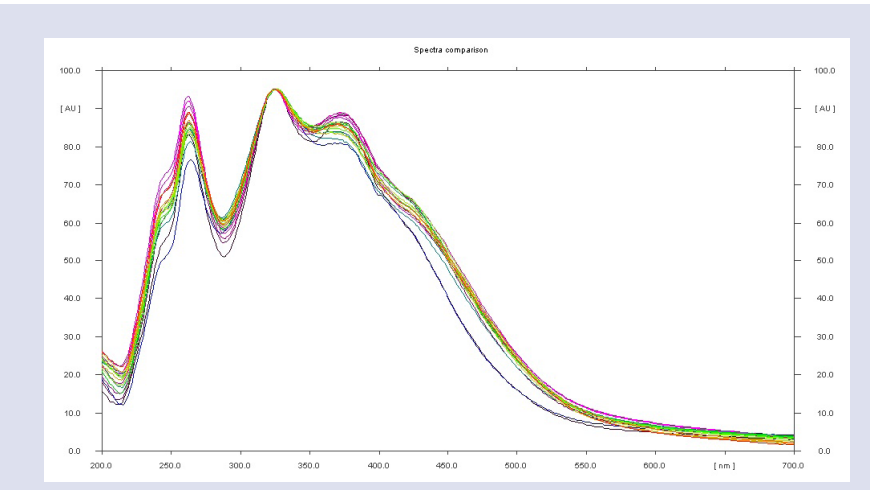

Figure 6: The absorption spectra of mangiferin in standard and sample bands.

\section{TLC analysis}

The TLC fingerprinting is demonstrated in Figure 5.

\section{Physicochemical constant determination}

The values of physicochemical parameter are displayed in Table 1. Loss on drying, moisture content, total ash, and acid-insoluble ash content were $8.62 \pm 0.13,8.16 \pm 0.14,6.82 \pm 0.09$, and $1.49 \pm 0.03 \%$ of dried weight, respectively. Ethanolic- and water-extractive values were $9.07 \pm$ 0.39 and $16.94 \pm 0.22 \%$ of dried weight, respectively.

\section{Method validation for quantified mangiferin content}

The method validation for this study was performed following ICH guidance, which comprised specificity, linearity, accuracy, precision, detection limit, and robustness. The results of validated parameters were displayed in Table 2. Specificity was determined in terms of peak identity and peak purity. The identities of the chromatogram bands of magiferin in the sample were compared by overlaying the absorption spectra with standard mangiferin (Figure 6). Moreover, peak purity was assessed by comparing the spectra of standard and samples at three different levels; peak start, peak apex and peak end positions. Considerable correlations, $r$ (start, middle) and $r$ (middle, end) $>0.9950$ were investigated by comparing the spectra of mangiferin standard and corresponding peaks in samples. 
Table 1: The pharmacognostic parameters of $A$. crassna leaves.

\begin{tabular}{cc}
\hline Parameter & $\begin{array}{c}\text { Content (\% by weight) } \\
\text { (grand mean } \pm \text { pooled SD) }\end{array}$ \\
\hline Loss on drying & $8.62 \pm 0.13$ \\
Water content & $8.16 \pm 0.14$ \\
Total ash & $6.82 \pm 0.09$ \\
Acid-insoluble ash & $1.49 \pm 0.03$ \\
Ethanolic extractive value & $9.07 \pm 0.40$ \\
Water extractive value & $16.94 \pm 0.22$ \\
\hline
\end{tabular}

Table 2: The validity of TLC-densitometry method and image analysis method.

\begin{tabular}{ccc}
\hline Parameter & TLC-Densitometry method & Image analysis method \\
\hline Specificity & & - \\
Peak purity & $\mathrm{r}>0.9950$ & - \\
Peak identity & $\mathrm{r}>0.9995$ & $450-1,950$ \\
Linearity Range (ng/spot) & $450-1,950$ & $\mathrm{y}=17.3402 \mathrm{x}+1409.2$ \\
Calibration equation & $\mathrm{y}=8.8423 \mathrm{x}+3873.7$ & $\mathrm{R}^{2}=0.9995$ \\
Correlation coefficient & $\mathrm{R}^{2}=0.9992$ & $100.26-102.52$ \\
Accuracy (\% Recovery) & $99.09-104.97$ & $0.61-3.48$ \\
Repeatability (\%RSD) & $1.52-3.35$ & $2.08-4.03$ \\
Intermediate precision (\%RSD) & $1.26-3.81$ & 131.38 \\
Limit of detection (ng/spot) & 119.11 & 398.11 \\
Limit of quantitation (ng/spot) & 360.93 & $2.39-2.59$ \\
Robustness (\%RSD) & $1.80-2.57$ &
\end{tabular}
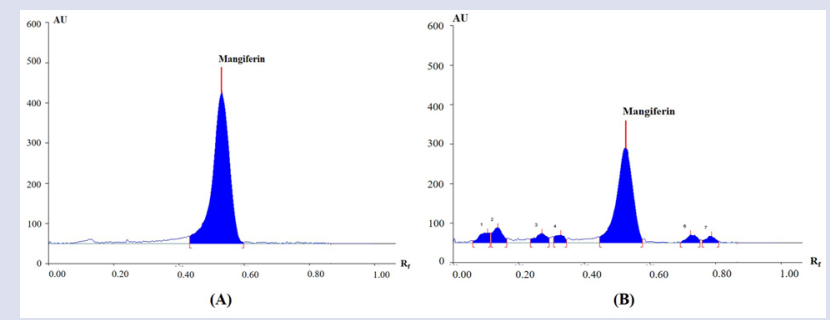

Figure 7: Densitogram of standard mangiferin $(A)$ and ethanolic extract of $A$. crassna leaves from Nan province (B).

However, the image analysis was limited in terms of specificity because this method was not able to generate the absorption spectra. The calibration curves of mangiferin by these two method were linear at the range of 450 to $1,950 \mathrm{ng} / \mathrm{spot}$. The average recoveries at three different concentrations of mangiferin agreed with the accuracy of the validated method. The repeatability and intermediate precision showed the acceptable precision of these two methods because RSD is less than 5\%. LOD and LOQ were estimated based upon the residual standard deviation of the regression line and the slope of the calibration curve. For robustness evaluation, the relative standard deviation of peak areas was calculated for little changing in ratio of the mobile phase composition. The RSD of robustness was computed to be less than $3 \%$ for all tests.

\section{Quantitative analysis of mangiferin}

The yield of $A$. crassna leaves ethanolic extract was $14.53 \pm 2.59 \%$ of dried weight. The mangiferin content of ethanolic extract was quantified via TLC-densitometry compared with TLC image analysis. The silica
$\mathrm{GF}_{254}$ TLC plate was used as stationary phase, while the mobile phase was composed of ethyl acetate: water: formic acid, at 34:6:4 v/v/v, respectively. A densitogram of A. crassna etanolic extract under UV $254 \mathrm{~nm}$ is shown in Figure 7 . The $\mathrm{R}_{\mathrm{f}}$ value of mangiferin band was approximately $0.42-0.48$. The densitometric scanning was recorded at $\lambda_{\max } 254 \mathrm{~nm}$. The amounts of mangiferin in $A$. crassna ethanolic extracted were determined using TLC-densitometry and TLC-image analysis, which were found to be $1.2992 \pm 0.5980$ and $1.3036 \pm 0.5874 \%$ of dried weight, respectively. Furthermore, the mangiferin contents by these two methods showed no statistically significant difference $(P>0.05)$.

\section{DISCUSSION}

Nowadays, the standardisation and authentication of medicinal plant materials is a crucial step for validating their therapeutic potential. Pharmacognostic studies are reliable, accurate and inexpensive ways to identify and evaluate crude drugs. Examination of the macroscopic and microscopic characteristics is the first step for establishing the identity and purity of herbal materials. Moreover, the authentication step should be done before any additional tests are performed.

The macro- and micro- morphological features of the A. crassna leaves were described. The microscopic characters of $A$. crassna were similar to A. agallocha, ${ }^{25}$ but unicellular trichome was not found in A. crassna. The results of these examinations could be beneficial as a basis for correct identification, collection and investigation of the plant. The physicochemical parameters are beneficial for controlling the medicinal plant quality. The investigation of these values is important in ascertaining adulteration or unsuitable management of the herbal drugs. The water determination and loss on drying are detected to represent the moisture in the crude drug, so the excessive water content and proper temperature might affect the growth of bacteria and fungus, which leads to spoilage. 
Total ash analysis was accountable for controlling the amount of admixture of inorganic substances either from the storage of crude drug or intended addition to conceal the appearance of the herbal drugs. Moreover, acidinsoluble ash defined the acid-insoluble inorganic matters, which can be found in the crude drugs. Finally, the extraction of the crude drug with solvent yields a solution containing many phytochemicals. The water and ethanol extractive values determined the quality and purity of the drug. The composition of these phytochemicals, in particular solvent, depends upon the polarity of the solvent and the nature of these chemicals. The chemical profiles displayed the composition of phytochemicals that could be used as markers for quality control of the medicinal plant.

The TLC-densitometry is a technique with accuracy and precision for quantitative and qualitative examination. The mangiferin content was quantified using the developed TLC-densitometric method. However, the quantitated content are higher than the actual yields $(0.0013 \%)$ that fractionated by Ray. ${ }^{7}$ In addition, the amount of mangiferin of A. crassna are closed to A. sinensis which performed on HPLC-MS. ${ }^{26}$ The difference in mangiferin content may be due to the period of plants, the geographic conditions where the leaves were cultivated, the duration of storage, or genetic variations. Moreover, the season of collection and the storage conditions may also lead to fluctuations in the magiferin content.

Image analysis for quantitation was performed due to its cost effectiveness and simplicity. The image analysis was processed using the TLC chromatogram image, which was then converted from pixel intensity to corresponding peak. The peak area was calculated by ImageJ free software. The quantitative analysis of mangiferin in A. crassna leaves using TLC image analysis was developed as well as validated. The amounts of mangiferin in A. crassna leaves by these two methods showed no statistically significant difference. The proposed TLC-densitometric and image analysis method were developed and validated for simultaneous quantitative analysis of mangiferin in the ethanolic extracts of A. crassna leaves collected from 15 different locations throughout Thailand. Thus, the method could be used for quality control of herbal raw materials as well as extracts.

\section{CONCLUSION}

The results from this present research provided useful information for identification and maintenance of $A$. crassna quality. Thus, the standardisation of $A$. crassna leaves will reduce adulteration in raw materials and should prove beneficial for the preparation of Thai Herbal Pharmacopoeia monograph from this plant.

\section{ACKNOWLEDGEMENT}

This research study was supported by the $100^{\text {th }}$ Anniversary Chulalongkorn University Fund for Doctoral Scholarships and the $90^{\text {th }}$ Anniversary of Chulalongkorn University, Rachadapiseksomphot Endowment Fund from Graduate School. We would also like to thank the Chulalongkorn University Drug and Health Products Innovation Promotion Centre, Faculty of Pharmaceutical Sciences, Chulalongkorn University for the use of laboratory facilities.

\section{ABBREVIATIONS USED}

TLC: Thin layer chromatography; WHO: World Health Organization; ICH: International Conference on Harmonisation of Technical Requirements for Registration of Pharmaceuticals for Human Use; LOD: Limit of detection; LOQ: Limit of quantitation.

\section{CONFLICT OF INTEREST}

The authors declare that there is no conflict of interest regarding the publication of this article.

\section{REFERENCES}

1. Song ZY. Modern Research on Chinese Herbal Medicine. Beijing, China: Peking Medical College and Peking Union Medical College Associated Press.1997.

2. Pranakhon R, Pannangpetch P, Aromdee C. Antihyperglycemic activity of agarwood leaf extracts in STZ-induced diabetic rats and glucose uptake enhancement activity in rat adipocytes. Songklanakarin J Sci Technol. 2011;33(4):405-10.

3. Sattayasai J, Bantadkit J, Aromdee C, Lattmann E, Airarat W. Antipyretic, analgesic and anti-oxidative activities of Aquilaria crassna leaves extract in rodents. J Ayurveda Integr Med. 2012;3(4):175-9.

4. Huda A, Munira M, Fitrya S D, Salmah M. Antioxidant activity of Aquilaria malaccensis (thymelaeaceae) leaves. Phcog Res. 2009;1(5):270-3.

5. Kakino M, Sugiyama T, Kunieda H, Tazawa S, Maruyama H. Agarwood (Aquilaria crassna) extracts decrease high-protein high-fat diet-induced intestinal putrefaction toxins in mice. Pharm Anal Acta. 2012;3:1-7.

6. Kakino M, Izuta $H$, Ito T, Tsuruma K, Araki Y, Shimazawa M, et al. Agarwood induced laxative effects via acetylcholine receptors on loperamide-induced constipation in mice. Biosci Biotechnol Biochem. 2010;74(8):1550-5.

7. Ray G, Leelamanit W, Sithisarn P, Jiratchariyakul W. Antioxidative Compounds from Aquilaria crassna Leaf. Mahidol J Pharm Sci. 2014;41(4):54-8.

8. Nag G, Das S, Das S, De B. Antioxidant, anti-acetylcholinesterase and antiglycosidase properties of three species of Swertia, their xanthones and amarogentin: A comparative study. Phcog J. 2015;7(2):117-23.

9. Hegazy M, Ngandeu F, Neguim G, Tane P, Mohamed A, Djemgou P et al. C-Glucoside xanthone from the stem bark extract of Bersama engleriana. Phcog Res. 2010;2(4):229.

10. Anila L, Vijayalakshmi NR. Flavonoids from Emblica officinalis and Mangifera indica-effectiveness for dyslipidemia. J Ethnopharmacol. 2002;79(1):81-7.

11. Gururaja GM, Mundkinajeddu D, Dethe SM, Sangli GK, Abhilash K, Agarwal A. Cholesterol esterase inhibitory activity of bioactives from leaves of Mangifera indica L. Phcog Res. 2015;7(4):355-62.

12. Ichiki H, Miura T, Kubo M, Ishihara E, Komatsu Y, Tanigawa K, et al. New antidiabetic compounds, mangiferin and its Glucoside. Biol Pharm Bull. 1998;21(12):1389-90.

13. Dineshkumar B, Mitra A, Manjunatha M. Studies on the anti-diabetic and hypolipidemic potentials of mangiferin (xanthone glucoside) in streptozotocininduced type 1 and type 2 diabetic model rats. Int J Adv Pharm Sci.2010;1(1):75-85

14. Ganogpichayagrai A, Palanuvej C, Ruangrungsi N. Antidiabetic and anticancer activities of Mangifera indica cv. Okrong leaves. J Adv Pharm Technol Res. 2017;8(1):19-24.

15. Muruganandan S, Srinivasan K, Gupta S, Gupta PK, Lal J. Effect of mangiferin on hyperglycemia and atherogenicity in streptozotocin diabetic rats. J Ethnopharmacol 2005;97(3):497-501.

16. Kumar BD, Krishnakumar K, Jaganathan SK, Mandal M. Effect of Mangiferin and Mahanimbine on Glucose Utilization in 3T3-L1 cells. Phcog Mag. 2013;9(33):72-5.

17. Gold-Smith F, Fernandez A, Bishop K. Mangiferin and Cancer: Mechanisms of Action. Nutrients. 2016;8(7)396.

18. Luczkiewicz P, Kokotkiewicz A, Dampc A, Luczkiewicz M. Mangiferin: A promising therapeutic agent for rheumatoid arthritis treatment. Med Hypotheses. 2014; 83(5):570-4

19. Telang M, Dhulap S, Mandhare A, Hirwani R. Therapeutic and cosmetic applications of mangiferin: a patent review. Expert Opin Ther Pat. 2013;23(12):1561-80.

20. Sato T, Kawamoto A, Tamura A, Tatsumi Y, Fujii T. Mechanism of antioxidant action of pueraria glycoside (PG)-1 (an isoflavonoid) and mangiferin (a xanthonoid). Chem Pharm Bull (Tokyo). 1992;40(3):721-4.

21. Vyas A, Syeda K, Ahmad A, Padhye S, Sarkar FH. Perspectives on Medicinal Properties of Mangiferin. Mini Rev Med Chem. 2012;12(5):412-25.

22. Leiro J, Arranz JA, Yáñez M, Ubeira FM, Sanmartín ML, Orallo F. Expression profiles of genes involved in the mouse nuclear factor-kappa $B$ signal transduction pathway are modulated by mangiferin. Int Immunopharmacol. 2004;4(6):763-78

23. World Health Organisation. Quality control methods for herbal materials Geneva: WHO. 2011.p.9-35.

24. The International Conference on Harmonisation of Technical Requirements for Registration of Pharmaceuticals for Human Use. ICH Harmonised Tripartite Guideline, Validation of Analytical Procedures: Text and Methodology Q2 (R1). Geneva: ICH. 2005.

25. Tang WP, Chen SS. Study on anatomical structure of leaf of Aquilaria agallocha. Guihaia. 2005;25(3):229-32.

26. Yu Q, Qi J, Yu H, Chen L, Kou J, Liu S, et al. Qualitative and Quantitative Analysis of Phenolic Compounds in the Leaves of Aquilaria sinensis Using Liquid Chromatography-Mass Spectrometry. Phytochem Anal. 2013;24(4):349-56. 
GRAPHICAL ABSTRACT

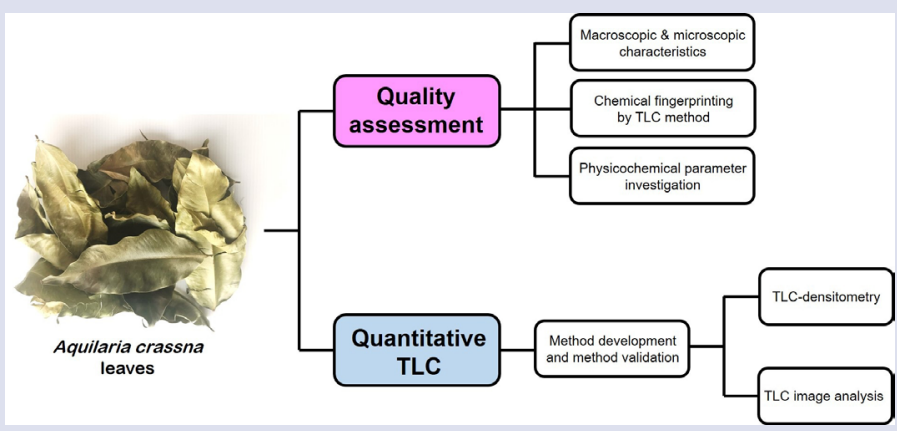

\section{ABOUT AUTHORS}

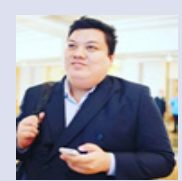

Worathat Thitikornpong: Is a Ph.D. candidate at College of Public Health Sciences, Chulalongkorn University. He graduated his Bachelor degree of Pharmaceutical Sciences and Master degree of Sciences in Pharmacognosy. His doctoral research concentrated on quality control and biological assessment of Aquilaria crassna leaves extract and mangiferin.

\section{SUMMARY}

- The extract of Aquilaria crassna leaves revealed various pharmacological activities as an anti-hyperglycemic, antipyretic, analgesic and laxative. Mangiferin was identified as an active compound in A. crassna leaves.

- This study provided macroscopical and microscopical characteristics as well as chemical fingerprinting which could be beneficial for correct identification, collection and investigation of the plant.

- In addition, the physicochemical parameters; loss on drying, water content, total ash, acid-insoluble ash, and extractive value, were evaluated for controlling the leaves of A. crassna quality.

- The validated TLC-densitometric and image analysis methods were developed for simultaneous quantitative analysis of mangiferin in the ethanolic extracts of $A$. crassna leaves. The amounts of mangiferin in $A$. crassna ethanolic extracts were determined using TLC-densitometry and TLCimage analysis, which were found to be $1.2992 \pm 0.5980$ and $1.3036 \pm 0.5874 \%$ of dried weight, respectively. In addition, the mangiferin contents by these two methods showed no statistically significant difference.

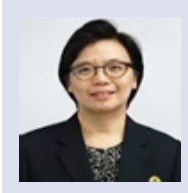

Boonsri Ongpipattanakul: Is an Assistant Professor at Faculty of Pharmaceutical Sciences, Chulalongkorn University. She takes the position of Director of CU Drug and Health Products Innovation Promotion Center. Her researches focused on protein characterization and quantitative analysis of medicinal plant extract.

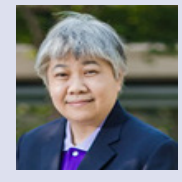

Chanida Palanuvej: Is an Assistant Professor at College of Public Health Sciences, Chulalongkorn University. She focused her researches on scientific evidence based - traditional Thai and alternative medicines. Her career involves herbal drug standardization, chemical qualitative/ quantitative analyses and biological activity evaluation. She has collaborated with Department of Thai Traditional and Alternative Medicine, Ministry of Public Health for establishing "Pharmacognostic Specification of Thai Crude Drugs" which have been printed as reference books in 2007 (Volume 1) and 2013 (Volume 2).

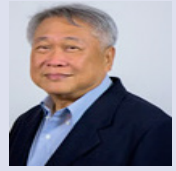

Nijsiri Ruangrungsi: Is an Associate Professor at College of Public Health Sciences, Chulalongkorn University. He pursued the career of pharmacognosy curriculum as well as research on chemistry of natural products. During 40 years of researches, he has got enormous experiences in plant taxonomy, phytochemistry and herbal medicine. At present, he still shares his body of knowledge and expertise in various opportunities. He is an expert in medicinal plants and pharmacognosy of Ministry of Public Health. He is appointed to be a committee in the National Science and Technology Development Board of National Science and Technology Development Agency (NSTDA).

Cite this article: Thitikornpong W, Ongpipattanakul B, Palanuvej C, Ruangrungsi N. Pharmacognostic Specification and Mangiferin Content of Aquilaria crassna Leaves. Pharmacog J. 2018;10(2):293-8. 